\title{
Study on the Construction of Library Information Service Platform based on Mobile Network
}

\author{
Xin $\mathrm{Li}^{1, \mathrm{a}}$ and Huanyu $\mathrm{Zhu}^{1, \mathrm{~b}^{*}}$ \\ ${ }^{1}$ Library, Beihua University, Jilin, China \\ alixin198282@163.com, b35780861@qq.com \\ ${ }^{*}$ Corresponding author
}

Keywords: Mobile reading; Information service; Self-help reading

\begin{abstract}
Purpose/significance]In the ubiquitous network environment, mobile reading is the important way for people to access information. The library is the servicer for the information, should pay attention to the service of mobile reading resources and the convenient reading experience, and should actively explore the mobile reading service model. [Method/process]In this paper, it analyzes the user's mobile reading demand and usage habits, expounds the construction process of the mobile information service model of Library in five aspects, such as unified user authentication login module, mobile library system, social reading cloud services, reference cloud platform and virtual library. [Result/conclusion]Through the construction of information service platform for mobile network based library information service, will be changed the focus of information service from the traditional fixed location service mode to the ubiquitous mobile reading service model, to provide library information resource inquiry service for readers based on mobile terminals. It will be promoted the mobile development of libraries, to satisfy the needs of increasing mobile reading and self-help reading for library information resources in mobile network environment.
\end{abstract}

\section{Introduction}

In recent years, with the continuous development of the network environment and the extensive application of multimedia information technology in the library, the mobile terminals such as smart phones are widely popularized, so the ecological environment and reading habits of teachers and students in Colleges and universities have undergone tremendous changes. Mobile reading has become the main way for people to obtain information, and created new development space for digital library information service.

In the ubiquitous network environment, the library is the servicer for the information, should pay attention to the service of mobile reading resources and the convenient reading experience, and should actively explore the mobile reading service model. Through the construction of information service platform for mobile network based library information service, will be changed the focus of information service from the traditional fixed location service mode to the ubiquitous mobile reading service model, to provide library information resource inquiry service for readers based on mobile terminals. It will be promoted the mobile development of libraries, to satisfy the needs of increasing mobile reading and self-help reading for library information resources in mobile network environment.

\section{Research on Mobile Reading Demand of Readers in Ubiquitous Network Environment}

Development of Ubiquitous Network Environment. In 1990s, ubiquitous computing is a new social network computing model,[1] through the use of mobile technology and wireless network technology, the spread and use of the media gradually diversified. In the ubiquitous network environment, documents such as text, image, audio and different carriers form diversified information services through web pages or APP. 
The channel of mobile network information and multimedia transmission, carrying the knowledge dissemination task, globalization, mobile, integrated, intelligent and personalized development of information sharing and multimedia communication, meet the readers' reading needs a new era of environment.

Analysis of Mobile Reading Needs and Behavior Habits of Users. In 2017, CNNIC released the " China Internet Development Statistics Report" pointed out that the number of Internet users in China has reached 731 million, mobile subscriber growth rate exceeded $10 \%$ for three consecutive years, $95.1 \%$ of the total number of Internet users, far more than desktop and notebook Internet access.

Through the report we can find, the rapid development of mobile Internet has changed our information ecology environment, users use mobile terminals to read and listen to and watch video and video resources in fragmented ways, the development of mobile network has seriously affected and changed the user's reading needs and behavior habits. [2,3]

The personality needs of cloud reading. In the ubiquitous network environment, users want to use different mobile device terminals through different operating platforms and network systems to access a variety of information resources, so as to pursue the best reading effect. Therefore, resource providers need to constantly explore new information service models, provide cloud reading services, and realize the reader's multi device compatible, multi system seamless mobile reading demand.

The trend of mobile resource access. Break through traditional resource access, time and space barriers to achieve free access to resources, and removable access. At present, Internet users basically have intelligent mobile terminals such as mobile phone or tablet, "mobile phone control" has become the people's normal life, the user's reading habits and method of acquiring knowledge is completely changed, mobile information demand is more and more intense.

The self-help information acquisition intention. In the mobile network environment, reading has broken through the limitation of time and space, and the users are more eager to obtain information by themselves, to achieve self-help reading experience, so as to enjoy independent reading and learning. With the rapid development of network and the emergence of social network platform, the desire of personalization has become a reality and habit, therefore, the information provider should provide self-service information service platform according to the user's wishes, and satisfy the reader's reading behavior needs.

\section{The Advantage of Constructing Information Navigation Service Based on Mobile Network}

With the application of the mobile terminal and the wireless network environment more widely, the necessity of building information resource service platform based on mobile network highlighted. The construction of information navigation service based on mobile network has many advantages, such as mobility, convenience, timeliness, richness and universality. It will attract more users and readers to the wave of mobile reading, it is an important way to obtain information for users, and plays a role in promoting the construction of a nationwide reading society. [4,5]

Mobility. Mobility is an important feature of the network information instant service platform. The digital library has already realized the information service of automation and network, but the traditional network information service can not realize the mobile access of information. Mobile library is no longer limited and rely on fixed computers to obtain information resources, can access, read, download and evaluate digital resources freely.

Convenience. Tablets computer and mobile-phones are smaller and easier to carry around. In the mobile network environment, users can access the Internet resources freely through the use of smart terminals, connected to $4 \mathrm{G}$ or wireless $\mathrm{WiFi}$ networks. Users can freely and anytime, anywhere access to information, not limited by time and space, and convenient to make information services more widely and easily.

Timeliness. The opening time of the library is limited, and outside the open time, readers can not enter the library to obtain information inquiry service. Even under the all-weather open network environment, because of the limitation of IP address, we can only access the information inquiry 
service of the library within the scope of the campus network. Mobile libraries use mobile Internet access as a LAN by using user authentication methods and techniques, have the characteristics of being everywhere and being absent. It can maximize the information service ability of the library.

Richness. With the gradual popularization of mobile communication network, the structure of the user's information demand has become the mainstream of the times from the traditional type to the digital and network. In the information age, mobile phone, as the most common mobile communication tool, has been a necessary part of the mobile phone users' lives by using mobile phones to obtain information through the $3 \mathrm{G}$ network. As a pocket digital library, mobile library has abundant information resources relying on traditional library, and it is the extension of traditional library.

\section{Construction of Library Information Navigation Service Model Based on Mobile Network}

Mobile self-service library information navigation service platform includes user terminal, user authentication login module, mobile library system, social reading service and reference of cloud platform and virtual library system consists of six parts. The specific model is shown in Fig. 1.

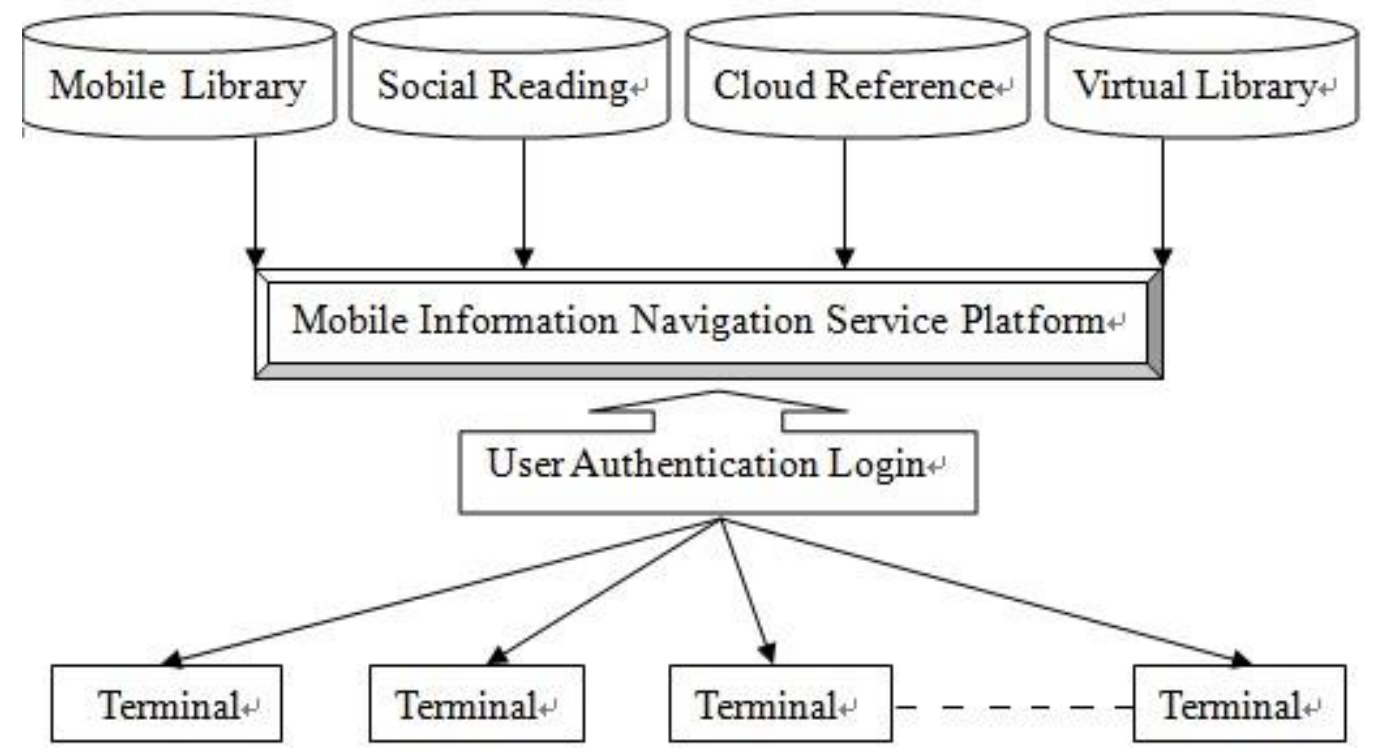

Figure 1. Information navigation service model of Library Based on mobile network

User Unified Authentication Landing Module. With the continuous development of information technology, most university libraries have established a variety of information resources access system. Each system will have its own user login verification module, which makes it easy for users to confuse their account password. Therefore, it is necessary to establish a unified user authentication landing platform to facilitate user authentication.

The user data of basic authentication landing platform use loan management platform of library resources, the other to access the system through a unified authentication and verification of all read circulation system to achieve the library login account password, This can guarantee the accuracy of the user's data, and also facilitate the user to use the same account password to log on the entire system platform of the library.

Mobile Library System Module. Relying on wireless technology and smart phones and other mobile terminals, mobile library can change the way they used to send text messages and multimedia data, began to develop WEB browsing, visual communication mode of the wireless internet. Libraries need deep processing to build up a standardized database for information resources in the library, and create rich, practical and unique web pages. Design simple composition, clear structure, reasonable classification, and even moderate font, more suitable for mobile terminal reading user service website.[6] 
The design of the mobile library system can use the same with the original library WEB system architecture and WEB development technology, many modules can be transplanted from the original WEB library query system, which can reduce the difficulty of construction of mobile phone library, reduce the implementation cycle, saving time and money.

Social Reading Service Module. While fully enjoying the spiritual enjoyment of mobile reading, more and more people are willing to share their achievements and insights. In the mobile network environment, the popularity of intelligent terminals, makes it easy for users to log on the mobile reading platform at any time, providing users with the space to participate actively. The need for free reading and sharing has come true. The library is the servicer for the information, in the ubiquitous network environment, in addition to providing mobile library resources to users, to provide users with mobile network a social reading environment. [7]

That is to say, social reading platform not only provides resource access services, but also provides a group reading mechanism for evaluation, recommendation, sharing and mutual evaluation. When users read resources in the social reading platform, they can also forward the information source and their understanding to their friends and their academic circle of friends, so as to realize the sharing and reuse of resources.

Reference of Cloud Platform. In recent years, the reference service has received extensive attention from the library. Referred to as the library's think tank and heart, the reference librarian is a transmitter of excellent literature and information resources.[8,9] The traditional reference service platform increases the interactivity while providing information consulting service, and meets the needs of users' consulting service.

In the mobile network environment, we build a reference service cloud service platform, which can form a global, online and real-time reference cloud service through the mobile network connection, to provide users with a more efficient and convenient service platform, by means of visualization techniques, to satisfy the user's real-time information resource requirements.

Navigation of Virtual Library. With the development of computer hardware and computer graphics technology, virtual reality technology is more and more widely used in scientific research, education, culture, entertainment and other situations.[10,11] Using virtual reality technology, the scene can be displayed through a three-dimensional image of the computer in a realistic virtual scene, providing an immersive visual experience for many visitors who cannot visit it.

In the way of virtual scenes, the traditional library has been limited by the construction area, so that users can enjoy more convenient and fun in the course of reading. Through the simulation of the real environment in the virtual library, the users can feel immersive and get the knowledge of the library from the perceptual point of view.

\section{Summary}

In the ubiquitous network environment, mobile reading will become the mainstream reading mode. The library is the servicer for the information, should pay attention to the service of mobile reading resources and the convenient reading experience, and should actively explore the mobile reading service model. It will be promoted the mobile development of libraries, to satisfy the needs of increasing mobile reading and self-help reading for library information resources in mobile network environment.

\section{Acknowledgements}

This paper is the relevant research result of the Educational Science Program in Jilin Province " Research on the teaching model reform of Library Literature Retrieval Course under the prosperity of network culture"(project number: GH170053); This paper is the relevant research result of the Educational Science Program in Jilin Province " Research on the cultivation of College Students' search skills from the Internet Perspective"(project number: GH16050). 


\section{References}

[1] X. Li: Journal of Library and Information Sciences in Agriculture, Vol:28 (2016) No.5, p.75-76. (In Chinese)

[2] G.H. Shi and Q.L. Xia: Journal of Library Science in China, Vol:40 (2014) No.2,p.78-91. (In Chinese)

[3] W. He and H. Li: Library and Information Service,Vol:59 (2015)No.7,p.39-47. (In Chinese)

[4] D.Q Dong, M. Wang and Q. Liu: Library and Information Service, Vol:59 (2015) No.10, p.131-136. (In Chinese)

[5] S.M. Guo and X. Liang: Journal of Academic Libraries, Vol:32(2014)No.1,p.90-96. (In Chinese)

[6] Y.J. Li, X.X. Zhang and K.Y, Zhang: Library and Information Service,Vol:59 (2015)No.6, p.90-96. (In Chinese)

[7] D.J. Zheng, S.X. Xuan and J.W. Shen: Journal of Academic Libraries, Vol:33 (2015) No.5, p.83-92. (In Chinese)

[8] H.X. Zhang: Journal of Library and Information Sciences in Agriculture,Vol:29 (2017)No.5, p.200-202. (In Chinese)

[9] B.R. Liu and H.J. Guo: Information Science,Vol:35 (2017)No.4,p.103-108. (In Chinese)

[10]X.G. Wei: Design and Applications of A Virtual Library Nevigating System(MS., University of Electronic Science and Technology,China 2015).p.31. (In Chinese)

[11]A.J. Xue and F. Li: Computer Systems \& Applications,Vol:25 (2016)No.4,p.252-257. (In Chinese) 